\title{
Methods of Controlling Power Consumption in Terms of Reforming Market Conditions
}

\author{
Anatoly Zamulko ${ }^{1}$, Yuri Veremiichuk ${ }^{2}$, \\ ${ }^{1-2}$ National Technical University of Ukraine "Kyiv Polytechnic Institute"
}

\begin{abstract}
In the article the analysis of existing approaches to power consumption management in terms of reforming energy sphere was conducted, main obstacles of implementing methods of controlling were defined with their suggested integrated use. Using an integrated approach to the management of power consumption will accelerate the processes of transition to market relations in the energy sector by creating an enabling environment and a more efficient operation of electricity consumers. The relevance of the robots for energy systems of Ukraine and Latvia is proved, and also the attention is focused on the problems of evaluation of the results of the use of methods of management and decision-making.
\end{abstract}

Keywords - Energy sphere, Power supply, Methods of controlling, Group of electric energy consumers, Power consumption management indicator.

\section{INTRODUCTION}

Energy sphere of every country is the industrial sphere, where the development and efficient application of its general assets influence the well-being, general level of country and its position in the world. Taking into account the issues of state regulating the balance of interests between state, power industry subjects and electric power consumers proves the confidence of investors in stable regulations for business activity in the industry.

Transfer from administrative management to new instruments of state impact, regulating the activity of different entities, characterized with various business legal forms, transfer to modern market model and supplier-consumer interaction system caused the necessity to approve matters of controlling and managing electricity consumption for efficient and reliable operation of energy system.

In present time there are many technical solutions, legal initiatives, economical and social transformations. All these issues are directed to solve certain tasks, reflecting one of the management components, but in order to reach the set target it is necessary to solve the complex of tasks. This work is aimed to represent the analysis of obstacles (barriers) to reach the efficient electric power consumption management, to classify tasks and certain strategic aims to overcome them.

\section{II.PROBLEM DEFINITIONS}

In the course of worldwide restructuring of energy sphere several market models have appeared, resulting from technical, economic and political development. Some models are valid, as, for example, NordPool or PJM, and others have been changed and improved in the course of time. Competitive relations evolvement in electric power sphere of the country is connected to introduction of model for full-scale competitive electric power market, significantly expanding the opportunities of meeting the requirements of suppliers, consumers and manufacturers of electric power and includes the range of segments with respective functions. However, in spite of market model, power system is being formed on the basis of main components, where major functions are being implemented:

- electric power wholesale market, where power purchase and sale are conducted;

- system for transferring and distributing electric energy;

- set of supplementary services to support security and safe power system activity, keeping the balance between demand and supply of electric energy and commercial accounting.

Thus, due to market conditions at simultaneous solving tasks for supporting security and economic efficiency increase for power system functioning it is necessary to take into account competition increase, such as transparency and optimal decision making, influencing profit and expenses of market participants. The impossibility to assess expenses is the reason why market subjects take the sole risk, mostly included into the price for electric energy, however, in competitive area possibilities of price manipulations will be minimized. Thus, in the relations market subjects should consider application of power consumption management system, namely in regulatory, technical and economic aspects.

Exact methods of electric power consumption management, due to their even attraction, have not currently deserved attention in Ukraine (however, they are widely popular in the USA). They are aimed to manage electric loading as required component to flatten the graphs of power system loading, decrease excessive energy consumption, decrease financial expenses by industrial enterprises etc. Consequently, efficient management of electric power application depends on complex consideration of basic matters: development and implementation of advanced system of charging for electric energy, which would stimulate the creation and integration of targeted electric power loading of consumers (consumers of electric energy regulators); creating models, methods and software to manage electric power loading of consumers and their electric power consumption; creating and supplying electric energy vendors and users with modern technologies for audit and electric power consumption management; development and integration of applicable regulatory basis to manage electric energy implementation. 


\section{ANALYSIS OF RECENT STUDIES AND PUBLICATIONS}

Issues of organizing and conducting efficient management are discussed in the studies of the following scientists: A. V. Prahovnik, A. K. Shidlovski, M. P. Kovalko, V. V. Michaylov, V. F. Nahodov, V. P. Rozen, V. P. Kalinchik, V. I. Taraday, E. V. Krikavskii, B. V. Papkov, V. G. Derzkii, V. R. Okorokov, V. I. Gordeev, P. I. Golovkin, A. Y. Machnitko etc., suggesting structural and technological, legal administrative, economic instruments and methods of consumption regulators. Thus, taking into account that many surveys try to combine these approaches into one complex with involving several methods, but implementation of general instrument system including present state of energy industry and relations between suppliers and consumers, and also the requirements of existing and perspective models of energy market were not reasonably investigated.

That is why, modern market transformations in electric power industry require measures to improve these approaches and integrate new techniques of optimum management for electric power consumption.

Survey objective is to improve management efficiency of electric power consumption by means of developing and creating assessment system for existing management methods and provide their complex implementation.

Thus to conduct scientific investigation on applying complex management methods of electric power consumption it is necessary to define the following targets:

- to analyze national regulatory basis on supporting management organization for electric power consumption and well-known management methods, allowing to create the foundation to design complex management basis;

- to study the characteristics of electric power market subjects, to determine management indicators for electric power consumption and conducts their structural analysis;

- to create procedure and assessment models of consumers for electric energy retail market in order to determine management segments including their peculiarities, impact factors to conduct clustering;

- to develop and improve assessment systems of electric power consumption management methods, using possibilities of market analysis to support functions and tasks of State Energy Supervision;

- to create principles of complex management for electric power consumption on different levels of power industry and conduct their respective improvement.

\section{EXPOSITION OF BASIC MATERIAL}

Today there are several possible variants of organizing demand management, including electric power consumption and capacity irregularities as components of demand assessment system for electric energy. Scientists respectively suggest different approaches to solve electric power management issues [1-3]: evaluating economic interest in creating maneuvering electric load, applying progressive system of electric power charges, applying modern technical appliances during generation, transferring and auditing electric energy, developing and approving respective regulatory documents, improving DSM technologies. The listed approaches are considered within certain region, industry, consumer including their peculiarities and applying management methods: economic, technical, legal administrative, communicative etc. It is also necessary to admit, that scientists due to the results of investigations established the concept of integrated electric power consumption management, presupposing estimation of electric energy and capacity, operative administration of electric power consumption modes due to the results of short-term and long-term planning in order to accomplish the stated modes of electric power consumption and efficient application of fuel resources by consumers [4]. It is important to admit, that management methods of electric power consumption were initially aimed to decrease loading of certain consumers (having this technical possibility) in the periods of maximum loads of power system and to certain extent caused flattening of electric load graph (ELG) for electric power system.

Application and integration of methods and approaches to manage electric power consumptions requires preliminary analysis of situation in the field, passing the transformation and being in transition phase. Significance of the task can be illustrated with the help of power systems of two post-soviet countries: Ukraine and Latvia, which were included to one system [5-6]. Analysis of ELG of the countries (Fig. 1) makes clear that the issue of flattening load is relevant, as breakdowns, picking and semi-picking consumption coincide (irregularity factor-F ).
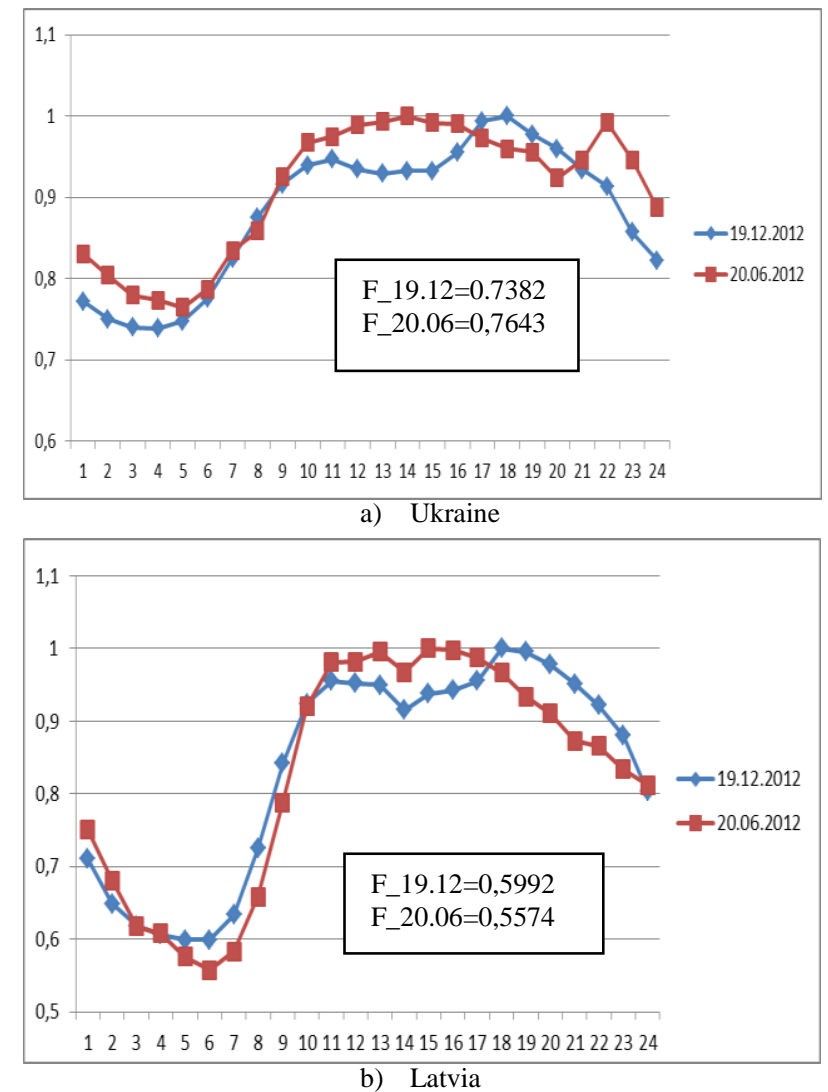

Fig. 1. Graph of hour load for maximum capacities. 
While analyzing the structure of electric power consumption [7] (Fig. 2) it is possible to define two groups of consumers, comprising over $60 \%$, necessary to be involved into managing electric power consumption, as such consumers will be able to make significant changes to mode of consuming and flattening ELG.

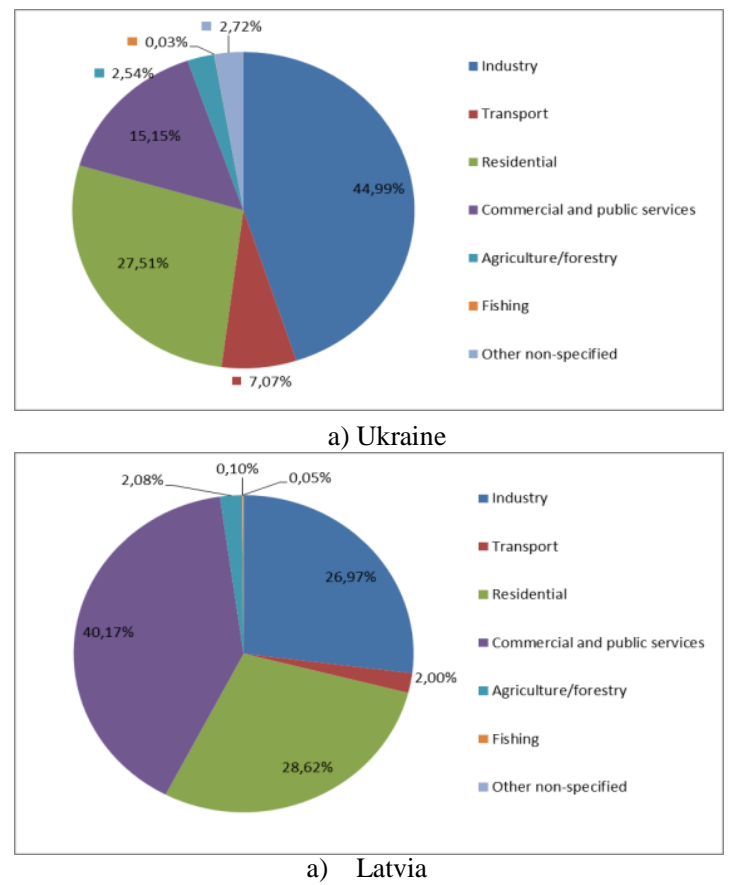

Fig. 2. Structure of consuming electric energy due to main groups of consumers.

The experience of many European and American countries should be taken into account, where main reasons for using policy of demand management were power crisis, rising costs on power resources, necessity to decrease negative environmental effect of power industry enterprises. But, what is more important, electric power consumer realized the necessity to conduct such policy, was ready for possible variant of course of events, and apart from these, he had the possibility to receive economic effect from integrating methods of demand management.

Moreover, it is important to consider, that demand management is the system of tasks and like every system it should contain control and feedback system organized for the processes, taking place in power sphere. Taking into account everything said above it is possible to conclude that integration of demand management methods shall have gradual character, using maximum acquired experience, improving possible existing methods and approaches to control electric power consumption on the basis of marketing principles of working with consumers.

Due to the scientific investigation directions the general structure of integrated electric power consumption management was created (Fig. 3), showing basic relations of power industry subjects, methods of managing and using mathematical tools to conduct modeling and data processing.
Considering the system of electric power consumption management as general complex of approaches, the methods were differentiated due to the following directions:

1. Methods of structural process management, applied during emergency situations or power deficit, where due to the order it is important to conduct unloading of power system. Herewith, such unloading can be performed automatically with the help of FLS or dispatch office personnel manually due to special emergency schedules.

2. Legal administrative methods of demand management is the set of system measures of administrative and legal impact on electric power consumers, aimed to establish certain restrictions or sequences of actions for consumers in case of revealing matters in power system in terms of covering power demand.

3. Economic methods of demand management in power system, which may include possibilities of charging systems to provide consumer with respective market (price) signals in order to impact the modes of consuming power energy during different time periods. Implementation of the management methods predefines establishment of economically justified charges and prices for goods and services, the level of which may include current and investment expenses of natural monopolies and respective amount of profit including economic status of consumers and level of effective demand. On this management stage the differential is establishment of charging menu for every segment of electric power retail market.

4. Final stage of creating integrated management system of electric power consumption is efficient implementation of possibilities for methods of establishing communication policy in power industry. The methods are aimed to provide efficient approval of demand and supply for subjects of area electric energy retail market, preserve and increase the share of electric power supply market, and in perspective - to acquire competitive benefits of electric energy due to other energy sources. Communication with consumers is very important for power supply companies, because energy sphere was always closed industry and this issue did not receive required attention. This task can be solved at the expense of data flows, which should be presented by companies. Receivers of communication policy, apart from consumers, are different contact audiences, namely company personnel, marketing brokers, shareholders, executive authorities (legislative and executive) etc.

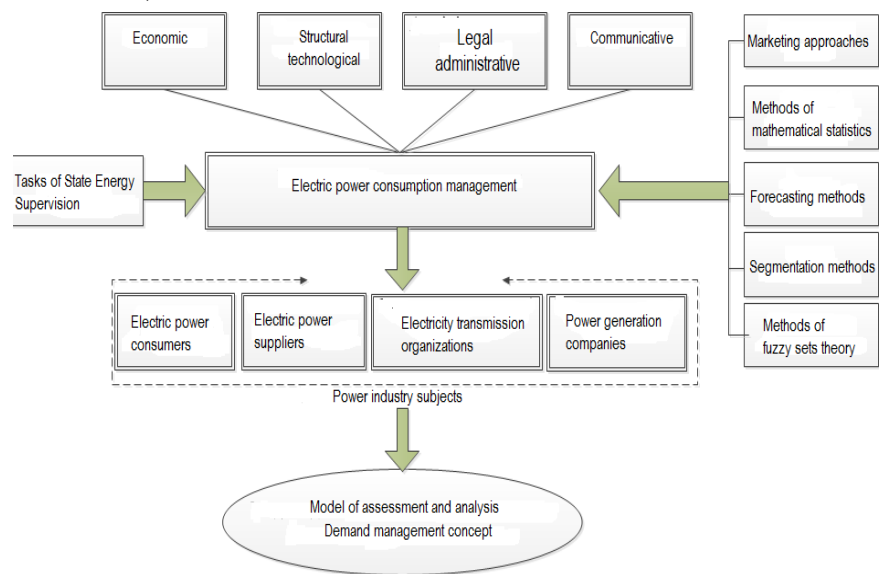

Fig. 3. Structure model of an integrated management of electric power consumption. 
Thus, the pyramid of complex power consumption management is a hierarchic model of applying (using) management methods to improve efficiency of power system operation in market conditions.

Due to the above presented it is possible to form the concept of hierarchical implementation of power consumption management in accordance with the conditions, determining the relations between electric power sphere subjects and electric power consumers. Due to the approach, the indicated methods are ranged starting from bottom levels to the higher ones by virtue of their application priority including regulatory system, specifying the application of the methods. They are usually overlapped partially and are interconnected, and at the same time, they can be grouped in the form of four separate blocks. Hierarchy concepts for using power consumption management methods can be presented in the form of pyramids (Fig. 4), reflecting the situation of applying power consumption management methods at present (Fig. 4a) and must be implemented in conditions of creating competitive environment in the area (Fig. 4b).

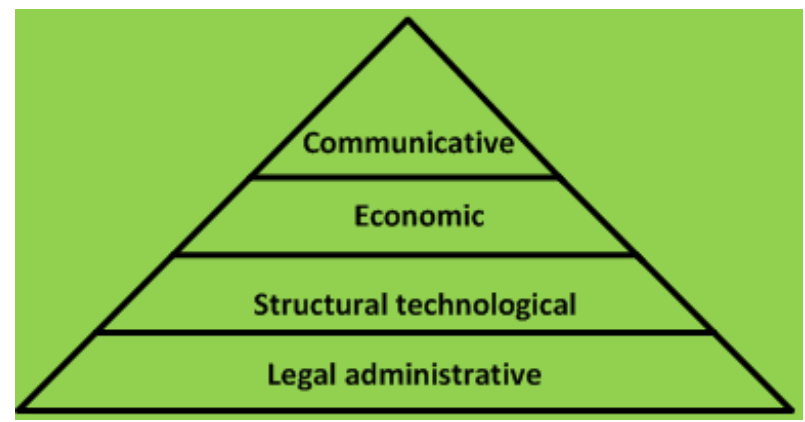

a) The modern condition of use of methods of management

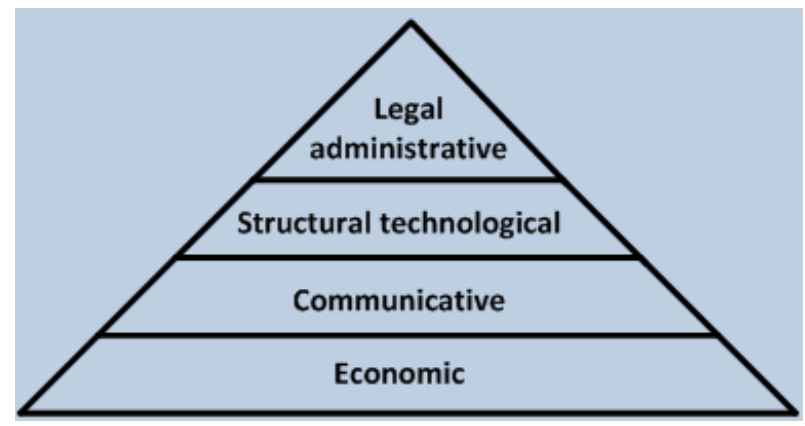

b) Use of management practices in market conditions

Fig. 4. Pyramid integrated management of electric power consumption.

In accordance with the predefined tasks the investigation was conducted and the following results were obtained:

- Using the conducted analysis of regulatory provision it is possible to say that power industry has wide range of regulatory documents and structure to prepare and supply legal basis, but the range of issues on electric power consumption management is left without attention or without required regulation. Issues of regulatory provision for electric power consumption management do not have system character and are provided partially both on state and regional levels. Providing respective level of electric power consumption management requires the improvement of regulations by means of introducing changes to respective legal acts [8];
- Investigating questions on forming indicators of electric power consumption management, including peculiarities of estimating subjects and consumers of power industry. Established suggestions for revealing indicators of electric power consumption management to conduct respective efficiency evaluation of demand management methods. On the basis of developed indicators and applying methods of indirect logics it is possible to receive integrated value of efficient impact for demand management methods [9];

- Considering issues for segmenting consumers of electric energy under the conditions of task hierarchy of demand management for electric energy and structural system of energy transition organizations. It was suggested to consider power industry consumers segmentation as the process to pass 3 levels of management on power market taking into account the possibility of using segmentation methods on different management levels of energy transition organizations [10-11];

- Forming assessment model to determine level of management level efficiency for electric power consumption for the group of electric power consumers, allowing to take management decisions due to the forecast results. In this case we consider the approach to form the model for evaluating economic management methods. Due to carrying out integrated approach it is necessary to conduct modeling on levels of hierarchy to receive general evaluation of management methods to consumer electric energy [12].

Respectively, for further improvements the following issues became important:

- to create unified model to assess and analyze possibilities and efficiency of applying management methods of electric power consumption for groups of electric energy consumers;

- to develop mathematical models of economic regulation of consumption modes for groups of electric energy consumers.

\section{V.CONCLUSIONS}

1. Power sphere reforming in any country requires detailed studying for ways to form and use efficiently the possibilities for legal, regulatory and technical provision of electric power supply management.

2. Important steps to introduce complex power supply consumption management are:

- establishment of structural model to realize complex power consumption management and provision of efficient impact for each component of model on management process;

- justification of respective indicators for power consumption management to use clustering methods and mathematical statistics to analyze indicators in the course of regions;

- establishment of the methods, allowing to solve cases of searching optimal solutions in terms of applying complex power consumption management in conditions of output information ambiguity and multi-criteria system, owning large amount of alternatives. 


\section{REFERENCES}

[1] A. Prakhovnik, E. Inshekov. "Efficient energy use in Ukraine: Main Problems and Solutions," in Demand Side Management: Proceedings. Alliance to Save Energy, 2001, pp. 19-35.

[2] O. Zgurovetz, G. Kostenko. "Effective methods for managing the consumption of electric energy," Problems of Energy, vol. 16, pp. 75-80, 2007.

[3] E. Krykavskyy, N. Kosar, L. Moroz Marketing of energy. Lviv, Lviv Polytechnic, 2001, pp.120-144.

[4] A. Prakhovnik Function-oriented optimization of energy consumption, Kiyv, NTUU “KPI”, 1981, pp 134-146.

[5] Augstsprieguma tīkls AS - Transmission System Operator, [Online]. Available: www.ast.lv

[6] National Commission for the State Regulation of Energy, [Online]. Available: www.nerc.gov.ua

[7] International Energy Agency, [Online]. Available: www.iea.org

[8] A. Zamulko and Y. Veremiichuk "Analysis of the regulatory framework of the management of power consumption", presented $11^{\text {th }}$ Int. Conf. Electromechanical Energy Systems and methods for modeling and optimization, Kremenchug, Ukraine, 2013.

[9] A. Zamulko and Y. Veremiichuk "Analysis of governance indicators electricity consumption," presented $4^{\text {th }}$ Int. Seminar Economic Security and the state of scientific and technological aspects of its implementation, Dnepropetrovsk, Ukraine, 2012.

[10] A. Zamulko, Y. Veremiichuk, Y. Chernetcka "Segmentation of retail electricity market using fuzzy logic algorithms," presented $10^{\text {th }}$ Int Conf. Modern Problems of Energy Research, Kyiv, Ukraine, 2012.

[11] A. Zamulko, Y. Veremiichuk. "Methodological bases of segmentation of the retail electricity market," Scientific and Technical Collection "Utilities cities", vol. 103, pp. 513-520, 2012.
[12] A. Zamulko and Y. Veremiichuk "Efficiency evaluation of using management methods of electric power consumption in conditions of uncertainty", presented $10^{\text {th }}$ Int. Conf. Control and management in integrated systems, Vinnitsa, 2012.

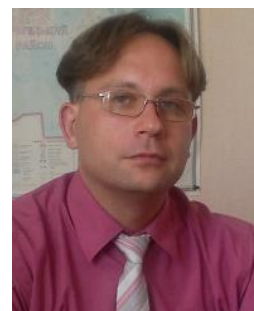

Anatoly Zamulko graduated from Institute of Energy Saving and Energy Management of NTUU "KPI". Defended a thesis on "Management of a power consumption with the use of tariffs on electric energy". Now works as associate professor at the Department of Power Supply and the Head of the State Inspectorate for supervision. Main directions of research: management of electric power consumption, the use of marketing techniques to solve problems in power.

Address: Str. Borschagivska, 103, Building 22, Kiev, 03056, Ukraine.

E-mail: zai_71@mail.ru

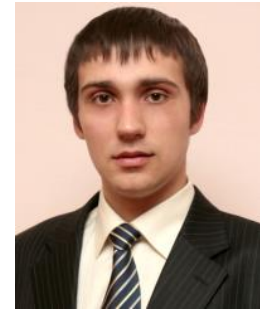

Yuri Veremiichuk received B. sc. and M. sc. degrees in computer science at the National Technical University of Ukraine "Kyiv Polytechnic institute" in 2008 and 2010, respectively. He is an $\mathrm{PhD}$ student at NTUU "KPI", Institute of Energy Saving and Energy Management Power Engineering. Now he works in research of methods of energy management in the electric power industry and optimization of the energy market.

Address: Str. Borschagivska, 103, Building 22, Kiev, 03056, Ukraine.

E-mail: abonne@i.ua 